\title{
Induction of Primary Antiphospholipid Syndrome in Mice by Immunization with a Human Monoclonal Anticardiolipin Antibody (H-3)
}

\author{
R. Bakimer,"* P. Fishman," M. Blank," B. Sredni," M. Djaldetti," and Y. Shoenfeld* \\ "Steinmet'z Research Unit of Autoimmune Diseases, Department of Medicine "B", Sheba Medical Center, Tel-Hashomer, 52621, Israel; \\ ${ }^{\ddagger}$ Faculty of Health Sciences, Ben-Gurion University of the Negev, Beer Sheva, Israel; ${ }^{8}$ Hematology Research Unit, Golda Medical Center, \\ Hasharon Hospital, Petach Tiqva, Israel; and "Cancer, and AIDS Institute, for Research, Department of Life Sciences, \\ Bar-Ilan University, Ramat Gan, 52900, Israel
}

\begin{abstract}
Antiphospholipid syndrome (APLS) is characterized by thrombocytopenia, thromboembolic phenomena, and recurrent fetal loss, associated with anticardiolipin antibodies (ACA) and/or lupus anticoagulant. The syndrome may be primary or may be associated with other conditions such as systemic lupus erythematosus.

We have previously shown the ability to induce APLS in naive mice following passive transfer of serum and monoclonal ACAs. Similarly we generated the secondary APLS in BALB/c mice following immunization with a pathogenic anti-DNA antibody. In the current study we report on the induction of primary APLS following immunization of BALB/c mice with a human monoclonal ACA (H-3). The mice developed high persistent titers of ACA. The APLS was characterized by prolonged activated partial thromboplastin time, low fecundity rate (21\% vs. 48\% of control immunized mice), high resorption index of fetuses (25\% vs. $3 \%$ ), and low weights of embryos and placentae.

Our study points to the ability of inducing primary APLS in naive mice. The induction of various presentations of APLS by different ACA may explain the diversity of clinical manifestations seen in patients with APLS. (J. Clin. Invest. 1992. 89:1558-1563.) Key words: autoimmunity • autoantibodies • experimental autoimmune diseases $\bullet$ antiphospholipid antibodies • systemic lupus erythematosus
\end{abstract}

\section{Introduction}

Primary antiphospholipid syndrome (PAPS) ${ }^{1}$ is characterized by the presence of anticardiolipin antibodies (ACA) or other antiphospholipid antibodies and/or lupus anticoagulant, thrombocytopenia, recurrent thromboembolic phenomena, recurrent fetal loss, and other diverse manifestations (1-6). Recently, we (6) and others (7) have shown the pathogenetic role

Address correspondence to Yehuda Shoenfeld, M. D., Department of Medicine "B", Sheba Medical Center, Tel-Hashomer, 52621, Israel.

Received for publication 6 August 1991 and in revised form 5 November 1991

1. Abbreviations used in this paper: ACA, anticardiolipin antibodies; APLS, antiphospholipid syndrome; APTT, activated partial thromboplastin; H-3, human ACA; KCT, kaolin clotting time; PAF, platelet-activating factor; PAPS, primary antiphospholipid syndrome; TBS, Tris base buffered saline.

J. Clin. Invest.

(c) The American Society for Clinical Investigation, Inc. $0021-9738 / 92 / 05 / 1558 / 06 \$ 2.00$

Volume 89, May 1992, 1558-1563 of the ACA, by inducing an experimental model of antiphospholipid syndrome (APLS) in naive mice following passive transfer of human and mouse monoclonal and polyclonal ACA to the tail vein of BALB/c and ICR mice (7). The APLS was exemplified by serological markers (ACA, prolonged activated partial thromboplastin time [APTT]), hematological findings (thrombocytopenia), and clinical manifestations (recurrent fetal resorptions-the equivalent of human fetal loss and smaller fetuses and placentae).

The aim of the present study was to report on the induction of PAPS by active immunization with a human ACA (H-3) (8). This model is analogous to our experiments on the induction of systemic lupus erythematosus (SLE) in mice using human anti-DNA antibody $(9,10)$.

\section{Methods}

Mice. BALB/c mice (8-10-wk old females) were purchased from the Sackler School of Medicine, Tel-Aviv University.

Antibodies. H-3 is a human monoclonal IgM (8), generated following fusion of peripheral blood lymphocytes of a healthy subject immunized with diphtheria and tetanus, with GM 4672 lymphoblastoid cell line $(8,9)$. The antibody binds to tetanus and diphtheria toxoids, cardiolipin, phosphatidylethanolamine, and phosphatidylserine (8). As control we used an irrelevant human IgM.

Induction of PAPS. BALB/c mice were immunized intradermally in the hind footpads (10) with $1 \mu \mathrm{g}$ of either H-3 MAb (43 mice) or IgM (50 mice) in CFA (Difco Laboratories, Inc., Detroit, MI). 3 wk later, boost injections were administered with the same amount of antibodies in isotonic PBS in the hind footpads.

Detection of antiphospholipid antibodies. Antiphospholipid activity in the sera of the immunized mice was detected by ELISA as follows: 96-well ELISA plates (Nunc, Roskilde, Denmark) were coated with phospholipid (cardiolipin, phosphatidylinositol, phosphatidylserine, phosphatidylcholine, platelet activating factor [PAF]) (Sigma Chemical Co., St. Louis, MO) at a concentration of $50 \mu \mathrm{g} / \mathrm{ml}$ in ethanol. The plate was left open to the air at $4^{\circ} \mathrm{C}$ until evaporation. After blocking of any remaining blockable sites with PBS and 5\% bovine serum (BS), serial dilutions $(1: 200-1: 3,600)$ of the mice sera in PBS $+2 \%$ BS were incubated for $2 \mathrm{~h}$. Excess sera were washed three times with PBS. Bound antibodies were detected using 1:1,000 dilution of goat antimouse Ig conjugated to alkaline phosphatase (Sigma) and the addition of its substrate $P$-nitro-phenyl-phosphate. Color was read in a Titertek (S. L. T. Laboratory Instruments, Vienna, Austria) ELISA reader at $405 \mathrm{~nm}$.

Detection of anti-ds-DNA. Anti-ds-DNA antibodies were determined according to Shoenfeld et al. (9). Briefly, polystyrene plates with 96 flat bottom wells (Nunc) were coated sequentially with poly-L-lysine ( $50 \mu \mathrm{g} / \mathrm{ml}$ in water), ds-DNA-2.5 $\mu \mathrm{g} / \mathrm{ml}$ TBS (Tris base buffered saline) and poly-L-glutamate $(50 \mu \mathrm{g} / \mathrm{ml})$. Washing between steps was performed using TBS with $0.05 \%$ Tween-20, to minimize nonspecific binding. The detection of the autoantibodies in the sera was done as described for anticardiolipin. 
Determination of anti-human IgM and anti-H-3 antibodies. ELISA plates were coated overnight with $2 \mu \mathrm{g} / \mathrm{ml}$ of IgM or $\mathrm{H}-3$ in $\mathrm{NaHCO}_{3}$, pH 9.6. Blocking was carried out by incubating with PBS and $0.5 \%$ gelatin. The rest of the procedure was carried out as above.

Inhibition of anticardiolipin and anti-ds-DNA binding. Sera at the dilution giving $50 \%$ of maximal binding to the antigen in question, were preincubated with the antigen, at different concentrations (100 $\mu \mathrm{g} / \mathrm{ml}-0.1 \mu \mathrm{g} / \mathrm{ml}$ ). The preincubation was carried out with cardiolipin, ds-DNA or a nonrelevant protein (BSA), in order to confirm the specific binding, or to show cross-reactivity of antibodies.

After incubation of the sera with the different inhibitors (DNA, cardiolipin) overnight at $4^{\circ} \mathrm{C}$, the remaining activity was tested by ELISA as detailed above. As control we used the serum incubated without the antigen, but with the appropriate volume of PBS instead. The percentage of inhibition was calculated as follows:

$\%$ inhibition $=\frac{(\mathrm{OD} \text { control }- \text { OD inhibitor }) \times 100}{\text { OD control }}$

Inhibition of serum binding to cardiolipin with platelets. Preincubation of sera from the immunized mice with different concentrations of fresh platelets was carried out in a tube for $18 \mathrm{~h}$. Cell concentration ranging from $2 \times 10^{6}$ to $1.25 \times 10^{9} / \mathrm{ml}$ of diluted sera $(1: 400)$ were incubated for $18 \mathrm{~h}$. Platelets were precipitated using high speed centrifugation. The remaining binding to cardiolipin and other antigens was determined using direct binding to antigen-coated plates as described above.

Inhibition of serum binding to platelets with cardiolipin. Binding to platelets was assessed using an ELISA technique. ELISA plates were coated with $1 \times 10^{6}$ platelets in $100 \mu$ of PBS. Coating was performed overnight in $4^{\circ} \mathrm{C}$. After washing, free binding sites were blocked using $1 \%$ BSA in PBS. Sera preincubated for $2 \mathrm{~h}$ with different concentrations of either cardiolipin or BSA were added to the plates. Excess binding was determined using anti-mouse IgG or IgM conjugated to alkaline-phosphatase.

Binding of serum immunoglobulin to platelet membrane proteins. The binding of serum immunoglobulin to platelet membrane proteins was analyzed employing the immunoprecipitation assay detailed by Coller et al. (11).

Blood cell counts. White blood cell and platelet counts from individual blood samples were quantified in diluted blood using a single optical cytometer (HC Plus Cell Control; Coulter Electronics Ltd., Luton, Beds., UK).

Detection of lupus anticoagulant. The presence of lupus anticoagulant was evaluated by the prolongation of APTT in a mixing test (5), adding 1 vol of plasma (whole blood mixed with Na-citrate $0.13 \mathrm{~mol} /$ liter, in a 9:1 ratio), to $1 \mathrm{vol}$ of actin and incubating for $2 \mathrm{~min}$ at $37^{\circ} \mathrm{C}$. Another volume of $0.02 \mathrm{M} \mathrm{CaCl}_{2}$ was added and the clotting time was recorded in seconds. The presence of the lupus anticoagulant was confirmed by the kaolin clotting time (KCT) (5).

Evaluation of pregnancy outcome. The number of vaginal plugs (indicating mating), the number of pregnancies (indicating fecundity), and the number of live embryos per successful pregnancy were studied.

Production of mouse monoclonal anticardiolipin antibodies. $5 \mathrm{mo}$ after immunization with $\mathrm{H}-3$, when constant high levels of anticardiolipin activity were detected in the sera of the immunized mice, one of the mice was killed and a hybridoma was generated from its splenocytes: the lymphocytes were fused with the NSO mouse myeloma cell line. Out of the many clones obtained, three (CAR 1-3) were chosen because of their ability to bind to cardiolipin, which was confirmed by inhibition assays.

Detection of the 16/6 Id in serum and monoclonal antibodies. To determine the presence of the $16 / 6 \mathrm{Id}$ of anti-DNA antibodies in sera of mice immunized with $\mathrm{H}-3$ and controls and on monoclonal anticardiolipin antibodies (CAR 1-3) we used the ELISA assay employing a specific rabbit anti-16/6 serum. Both methods were detailed previously by us $(12,13)$.

\section{Results}

Two-month-old female BALB/c mice $(n=43)$ were immunized with the human IgM monoclonal anticardiolipin antibody H-3. One month after the booster injection, high titers of anticardiolipin antibodies could be detected in the sera. Representative results are depicted in Fig. $1 a$. Fig. $1 b$ shows that the sera also contained antibodies to other phospholipids. The control group, which was immunized with human IgM, exhibited no antiphospholipid activity (Fig. 1, $a$ and $b$ ).

Since the sera of the mice also contained anti-ds-DNA antibodies we employed competition assay to determine whether these antibodies are individual antibodies or polyspecific immunoglobulins.

Fig. $2 a$ shows a similar inhibition of binding of the serum to DNA when incubated before the ELISA with cardiolipin (70\% inhibition) or DNA (60\% inhibition). In contrast, only cardiolipin inhibited (40\%) the binding of the serum to cardiolipin, while DNA failed to compete for this binding (Fig. $2 b$ ).
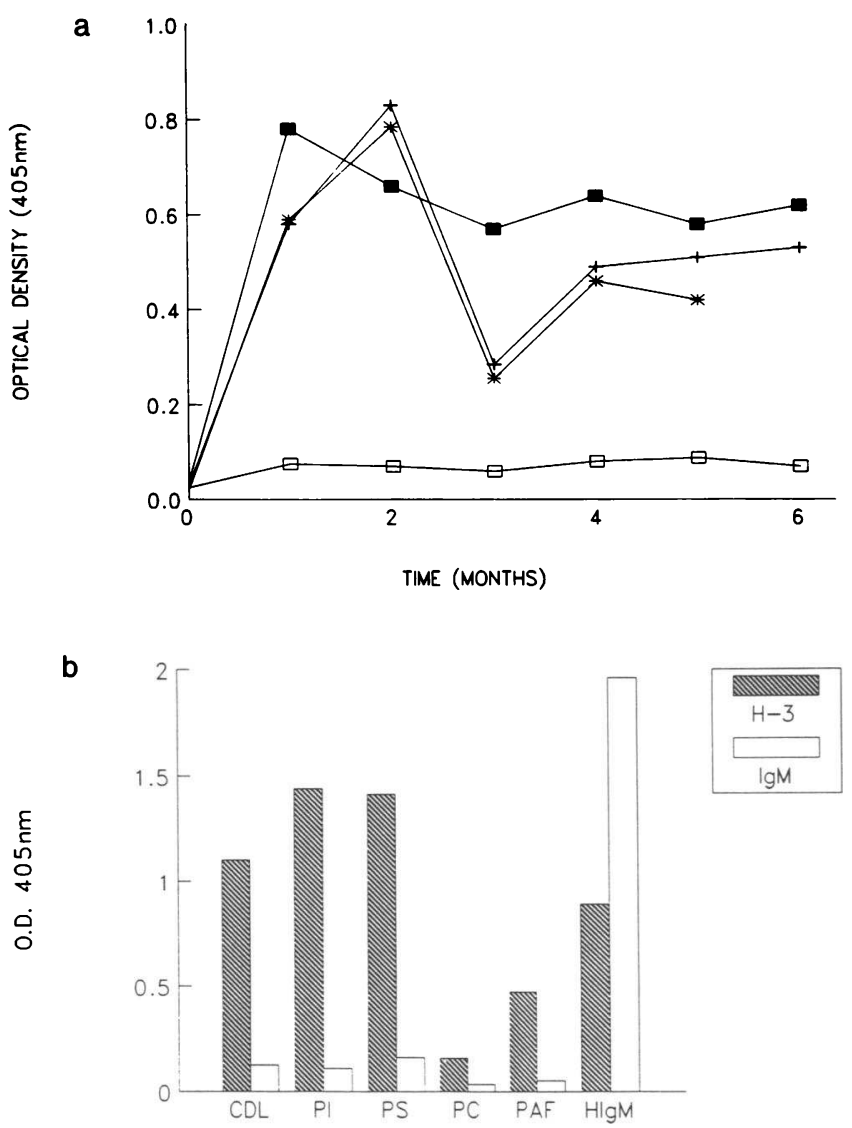

Figure 1. (a) Titers of anticardiolipin antibodies in the sera of representative mice $\left(a,+,{ }^{*}\right)$ immunized with $\mathrm{H}-3$ (human monoclonal anticardiolipin antibodies), and control $\operatorname{IgM}(\square)$, during a period of 6 mo following booster injection. (b) Detection of antiphospholipid antibodies ( $C D L$, cardiolipin; $P I$, phosphatidyl inositol; $P S$, phosphatidyl serine; $P C$, phosphatidyl cholin; and $P A F$, platelet activating factor) in ELISA. H-3 denotes sera of mice immunized with human anticardiolipin antibody $\mathrm{H}-3$. Open bars indicate titers of sera of mice immunized with control human IgM $(H I g M)$. Last row depicts titers of anti-human IgM in both groups of mice, showing that immunization was effective in $\mathrm{H}-3$ and $\mathrm{H}-\mathrm{IgM}$ immunized groups. 

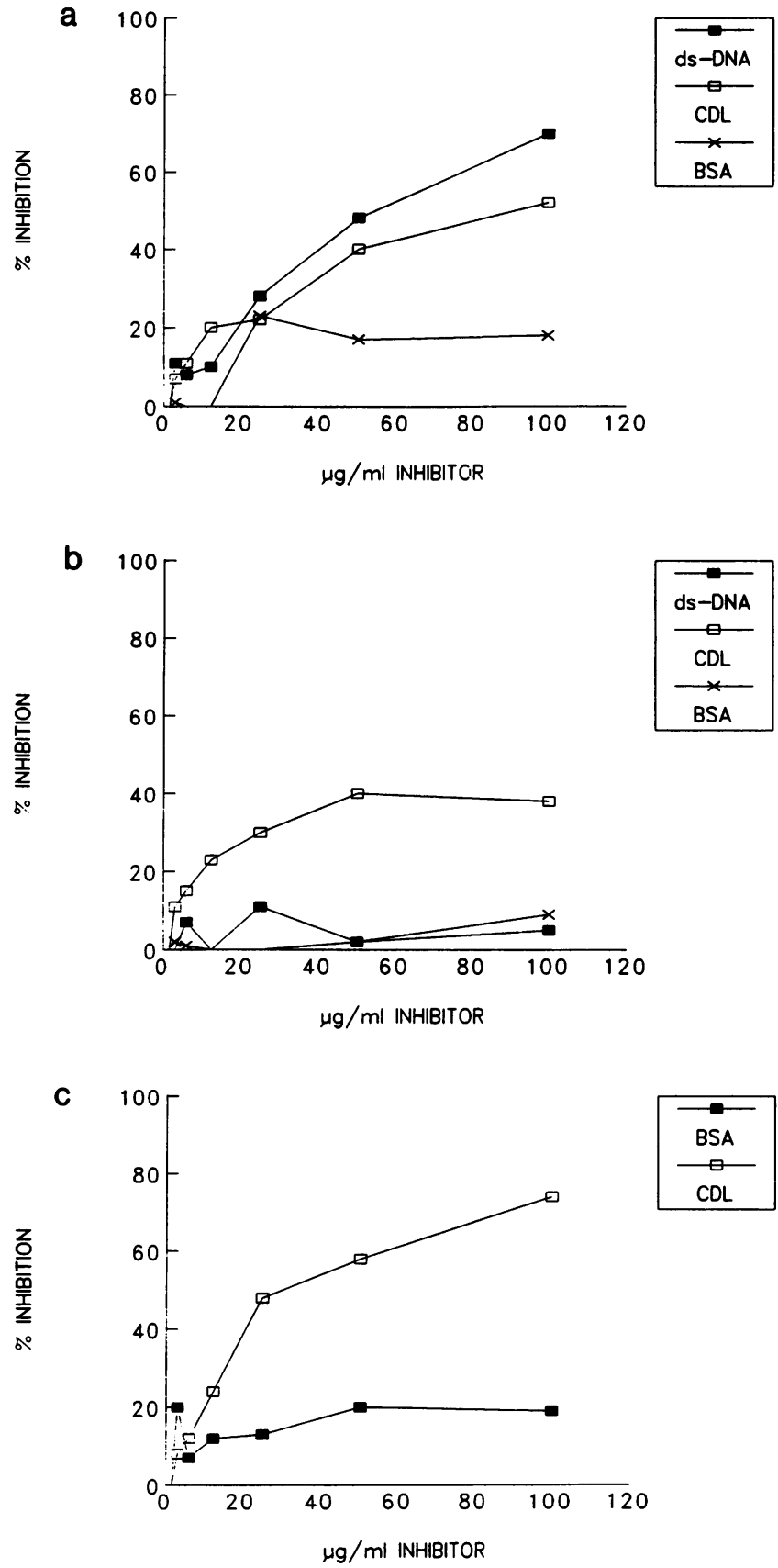

Figure 2. (a) An ELISA assay depicting inhibition of binding of a mouse serum to DNA with various concentrations of DNA (a) and cardiolipin (ם). A similar inhibition is noted with both competitors. (b) An ELISA assay in which the binding of a mouse serum to cardiolipin is inhibited by cardiolipin in solution. DNA failed to inhibit the reaction. $(c)$ Inhibition of binding of serum immunoglobulins to platelets by a prior incubation with cardiolipin.

The $\mathrm{H}-3$ as well as the IgM-immunized mice developed anti-human IgM antibodies (O.D. $405 \mathrm{~nm}$, mean \pm SD, $0.64 \pm 0.056$ vs. $1.67 \pm 0.029$, respectively) but only the group immunized with H-3 developed an anti-H-3 activity (O.D. 405 $\mathrm{nm}$, mean $\pm \mathrm{SD}, 1.33 \pm 0.1$ vs. $0.17 \pm 0.017$, respectively). Although a high titer of anti-ds-DNA could be determined in the sera of the mice immunized with H-3, neither $16 / 6$ Id was detected nor signs of SLE (e.g., accelerated erythrocyte sedimentation rate, leukopenia, proteinuria) (10) could be re-
Table I. Clinical Findings in Mice Immunized with Anticardiolipin $\mathrm{Ab}(\mathrm{H}-3)$ or a Control IgM

\begin{tabular}{lcc}
\hline \multicolumn{1}{c}{ Sign } & H-3 & IgM \\
\hline Fecundity* & $9 / 43=(21 \%)$ & $24 / 50=(48 \%)$ \\
No. of live embryos/pregnancy & $4.8 \pm 2.3$ & $8 \pm 2$ \\
R (resorptions) $(\% R=$ R/R + F) & $25 \pm 13$ & $3 \pm 5$ \\
APTT (seconds) & $57 \pm 11$ & $30 \pm 4$ \\
KCT (seconds) & $121 \pm 6$ & $75 \pm 3$
\end{tabular}

${ }^{*}$ No. of pregnancies. ${ }^{\ddagger}$ APTT is measured in plasma in the presence of actin and $\mathrm{CaCl}_{2}$.

corded in the immunized mice. In accordance with the high titers of anticardiolipin antibodies in the sera, prolongation of the APTT was noted (57 $\pm 11 \mathrm{~s})$, in comparison to the normal APTT measured in the plasma of mice immunized with the control IgM (30 \pm 4 s) (Table I). Compatible results were achieved with the KCT test ( $121 \pm 6$ vs. $75 \pm 3 \mathrm{~s})$. No thrombocytopenia could be noted in any of the immunized mice. However, preincubating the sera of the mice immunized with anticardiolipin antibody with platelets, decreased the anticardiolipin antibody activity of the serum in a dose-dependent manner (Table II). Similarly, the binding of the sera to platelets could be inhibited by a prior incubation with cardiolipin (Fig. $2 c$ ). We failed to demonstrate any binding of serum immunoglobulins to proteins employing a radioimmunoprecipitation assay (11) with platelet membrane protein (data not shown).

A lower fecundity rate was observed in the females immunized with $\mathrm{H}-3(21 \%$ vs. $48 \%)(P<0.005)$ (Table I), although there was no decrease in the number of vaginal plugs (indicating mating). Table I shows that a high percentage of resorptions could be found in the animals immunized with H-3 (25 \pm 13 vs. $3 \pm 5$ ).

A decrease in the mean $( \pm \mathrm{SD})$ number of live embryos was also noted (4.8 \pm 2.3$)$ among the mice immunized with anticardiolipin antibody (vs. controls $8 \pm 2$ ).

Fig. $3 a$ shows $100 \%$ fetal resorption in a representative uterus derived from a mouse immunized with $\mathrm{H}-3$ (top), as compared to a uterus from a nonpregnant mouse (bottom). According to the resorption size we may conclude that the resorption took place in an early gestational stage.

In Fig. $3 b$ deformed uterus, resorptions, and a low number of embryos in a mouse immunized with H-3 are depicted com-

Table II. Cross-reactivity of Mouse Anticardiolipin Antibodies to Platelets

\begin{tabular}{lcc}
\hline Platelet count & Anticardiolipin titer & Anti-BSA titer \\
\hline (Numbers $/ \mathrm{ml})$ & (OD 405 nm) & (OD 405 nm) \\
$2 \times 10^{6} / \mathrm{ml}$ & 1.127 & 0.398 \\
$1 \times 10^{7} / \mathrm{ml}$ & 1.164 & 0.591 \\
$5 \times 10^{7} / \mathrm{ml}$ & 0.856 & 0.547 \\
$2.5 \times 10^{8} / \mathrm{ml}$ & 0.689 & 0.415 \\
$1.25 \times 10^{9} / \mathrm{ml}$ & 0.322 & 0.553
\end{tabular}

Preincubation of the serum with platelets decreased anticardiolipin activity in a dose-dependent manner. 

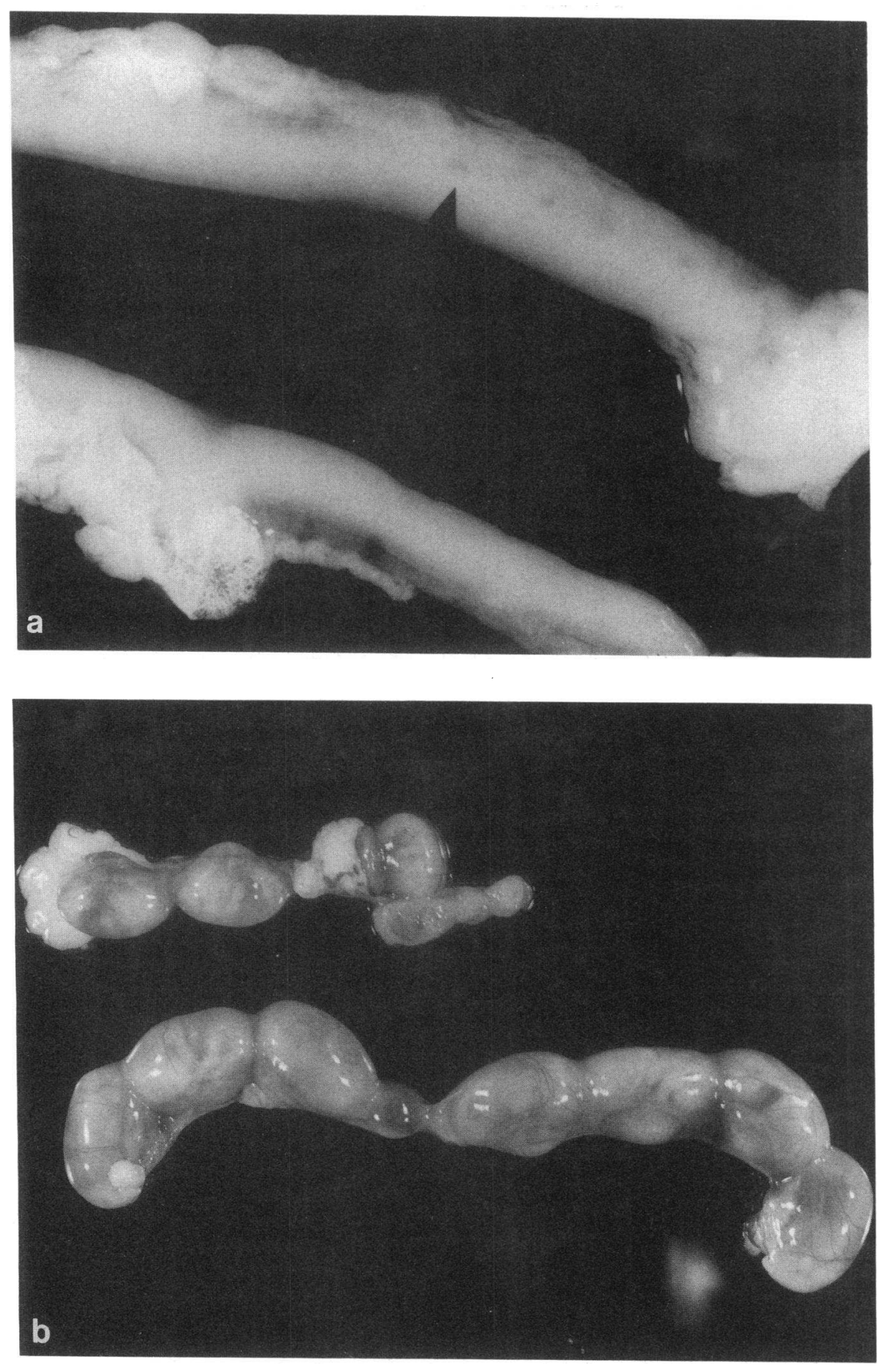

Figure 3. (a) Uterus of a mouse immunized with anticardiolipin (H-3) (top) as compared to a uterus of a nonpregnant mouse (bottom). The arrow indicates resorption at a very early stage of pregnancy. $(b)$ Uterus of a mouse immunized with anticardiolipin (H-3) (top), and a uterus derived from a mouse immunized with a control IgM (bottom). One can see deformations and few embryos in the mice immunized with $\mathrm{H}-3$ (top). pared to a normal uterus derived from a mouse immunized with IgM. Observations of placentae of $\mathrm{H}-3$ immunized mice revealed hemorrhages, whereas placentae of an IgM immunized mice contained a bright cap (the decidua) on their surface (data not shown).

Using the splenocytes of one of the $\mathrm{H}-3$ immunized mice in the hybridoma technique we generated several monoclonal antibodies with anticardiolipin activity. One of the monoclonal antibodies (CAR-1) was purified and its specific activity to cardiolipin was confirmed using inhibition assays. A 70\% inhibition was achieved by preincubating CAR-1 with $100 \mu \mathrm{g} / \mathrm{ml}$ of cardiolipin. The monoclonal antibody was also shown to have anticoagulant activity, prolonging the APTT of a normal plasma from $36 \mathrm{~s}$ up to $80 \mathrm{~s}$ when added to the complex (Fig. 4). The CAR antibody was found to be negative for the $16 / 6$ antiDNA idiotype.

\section{Discussion}

In a previous study (6) we were able to confirm the pathogenicity of the anticardiolipin antibodies. Passive transfer of purified serum and monoclonal anticardiolipin antibodies led to the induction of the APLS in mice exemplified by a recurrent fetal loss, thrombocytopenia, and the presence of the serological markers. 




Figure 4. Anticoagulant activity of mouse monoclonal anticardiolipin (CAR-1). APTT was measured in seconds when different amounts of the antibody (CAR) were added to a normal plasma. The open bars indicate an irrelevant mouse monoclonal immunoglobulin.

In another earlier study we showed the induction of secondary APLS associated with clinical manifestations of SLE. The latter was achieved after immunization with an anti-DNA monoclonal antibody (Blank, M., I. Krause, M. Ben-Bassat, and Y. Shoenfeld, manuscript submitted for publication). In the current study we report on the induction of primary APLS in mice after immunization with a human monoclonal anticardiolipin antibody $(\mathrm{H}-3)$.

After immunization, the mice developed anticardiolipin antibodies by themselves, titers of which remained constantly high for several months. The method of induction was similar to our previous report on the induction of experimental SLE (10) after immunization with a pathogenic anti-DNA antibody (14). In addition to our present knowledge of the characteristics of APLS in humans, in this experimental model of PAPS we noted a significant low fecundity rate ( $21 \%$ vs. $48 \%)$. The mice became pregnant with a lower number of live embryos in comparison to mice immunized with a control $\operatorname{IgM}(4.7 \pm 2$ vs. $8 \pm 2$; see Table I), higher resorption rate ( $25 \pm 13$ vs. $3 \pm 5 \%$ ), and evidence also for the induction of lupus anticoagulant as presented in APTT prolongation (Table I). Our studies support the notion of the existence of various types of APLS, most probably induced also in humans by different autoantibodies (e.g., monospecific antibodies binding to cardiolipin only, or polyspecific binding to cardiolipin and DNA as well as to other autoantigens). Other possible explanations of the wide diversity of clinical manifestations in APLS, entail other ligand binding characteristics such as binding avidity, isotype differences (e.g., IgG vs. IgM subclasses), and the existence of pathogenic versus nonpathogenic anticardiolipin idiotypes (14). The last possibility was recently demonstrated when we employed two antiidiotype antibodies directed against anticardiolipin antibodies derived from an active patient with SLE and from a healthy subject carrying a natural ACA (Cohen, J., R. Bakimer, $M$. Blank, and Y. Shoenfeld, manuscript submitted for publication).

In our case, immunization with the human ACA (H-3) most probably induced the production of $\mathrm{Ab} 2$ (i.e., anti-anticardiolipin) and $\mathrm{Ab} 3$ (i.e., anti-anti-anticardiolipin) which practically is the mouse anticardiolipin. From the competition studies it seems that the latter antibodies do cross-react with DNA. Such cross-reactive antibodies were reported in SLE and usually represent antibodies with low avidity to DNA $(15,16)$. Support for the cross-reactivity of the serum antibodies is given by the binding capacity properties of the CAR-1 mouse monoclonal antibody derived from the splenocytes of the immunized mice. These results remind our previous studies with sera of SLE patients (17) and human monoclonal anti-DNA antibodies (18).

The fact that the binding of the mouse sera to DNA was inhibited by both DNA and cardiolipin, while the binding to cardiolipin was inhibited only by cardiolipin itself, may point to the existence of two populations of induced autoantibodies: (a) polyspecific that cross-react with DNA and cardiolipin (most probably to the sugar phosphate backbone of DNA); and (b) monospecific anticardiolipin. The latter might be the pathogenic one that is responsible for the PAPS.

Why didn't our mice with PAPS and anti-DNA antibodies develop SLE or nephritis? It might be attributed at least to two features of the antibodies induced, which are not associated with nephritis: (a) the anti-DNA antibodies are of the low avidity type $(15,16)$; and $(b)$ the antibodies lack a pathogenic idiotype such as the $16 / 6 \operatorname{Id}(10,12,14,19,20)$. Previously (19), we showed the importance of the $16 / 6$ Id in the ability of antiDNA antibodies to induce experimental SLE with nephritis in mice.

One of the hallmarks of APLS is thrombocytopenia (2-5). In our mice we could not find low platelet counts, although in our previous studies with passive transfer of ACA, thrombocytopenia was clearly shown (6). However, we could confirm the binding of serum immunoglobulins to platelet's phospholipids. This binding was inhibited by prior incubation with cardiolipin. In contrast the sera did not react with platelet membrane proteins. We have no explanation why thrombocytopenia did not develop, but it is conceivable that a longer follow-up of these mice may disclose this pathology too.

Our induced APLS model shows the ability to induce ACA via idiotypic network employing antibodies with molecular mimicry to the nonimmunogenic molecule of cardiolipin. The induction actually confirms the pathogenic potential of ACA, shown by us previously following a passive transfer of ACA (6). In this case the pathogenic ACA were generated de novo by the immunized mice. Last but not least, this model may be employed to determine the efficacy of both preventive measurements as well as novel therapeutic agents.

\section{Acknowledgments}

We acknowledge the receipt of the H-3 monoclonal antibody used in this study, which was a gift from Dr. A. Hohmman, Flinders Medical Center, South Australia. We are indebted to Mrs. Shira Lancry for secretarial work and to Mr. Paul Hofman for the art work.

This work was supported by the Basic Research Foundation, Israel Academy of Sciences and Humanities.

\section{References}

1. Harris, E. H., A. N. Gharavi, M. L. Boey, S. Patel, C. G. Macworth-Young, and G. R. V. Hughes. 1983. Anti-cardiolipin antibodies: detection by radioimmunoassay and association with thrombosis in systemic lupus erythematosus. Lancet. ii:1211-1214.

2. Macworth-Young, C. 1990. Antiphospholipid antibodies: more than just a disease marker? Immunol. Today. 11:60-64.

3. Sammaritano, L. R., A. E. Gharavi, and M. D. Lockshin. 1990. Antiphospholipid antibody syndrome: immunologic and clinical aspects. Semin. Arthritis Rheum. 20:81-96.

4. Asherson, R. A., M. A. Khamashta, J. Ordi-Ros, R. H. W. M. Derksen, S. J. Machin, J. Barquinero, H. H. Outt, E. N. Harris, M. Vilardell-Torres, and 
G. R. V. Hughes. 1989. The "primary" antiphospholipid syndrome: major clinical and serological features. Medicine (Baltimore). 68:366-374.

5. Alarcon-Segovia, D., and J. Sanchez-Guerrero. 1989. Primary antiphospholipid syndrome. J. Rheumatol. 16:482-488.

6. Blank, M., J. Cohen, V. Toder, and Y. Shoenfeld. 1991. Induction of anti-phospholipid syndrome in naive mice with mouse lupus monoclonal and human polyclonal anti-cardiolipin antibodies. Proc. Natl. Acad. Sci. USA. 88:3069-3073.

7. Branch, D. W., D. J. Dudley, M. D. Mitchell, K. A. Creighton, T. M. Abott, E. Hammond, and R. A. Daynes. 1990. Immunoglobulin G fractions from patients with antiphospholipid antibodies cause fetal death in BALB/c mice: a model for autoimmune fetal loss. Am. J. Obstet. Gynecol. 163:210-216.

8. Sutjita, M., A. Hohmman, R. Comacchio, M. L. Boey, and J. A. Bradley.

1988. A common anti-cardiolipin antibody idiotype in autoimmune disease: identification using a mouse monoclonal antibody directed against a naturally occurring antiphospholipid antibody. Clin. Exp. Immunol. 74:110-114.

9. Shoenfeld, Y., S. C. Hsu-Lin, J. E. Gabriels, L. E. Silberstein, B. C. Furie, B Furrie, B. D. Stollar, and R. S. Schwartz. 1982. Production of autoantibodies by human-human hybridomas. J. Clin. Invest. 70:205-208.

10. Mendlovic, S., S. Brocke, Y. Shoenfeld, M. Ben-Bassat, A. Meshorer, R. Bakimer, and E. Mozes. 1988. Induction of a systemic lupus erythematosus like disease in mice by common anti-DNA idiotype. Proc. Natl. Acad. Sci. USA. 85:2260-2264.

11. Coller, B. S., E. I. Peerschke, L. E. Schudder, and C. A. Sullivan. 1983 Studies with a murine monoclonal antibody that abolishes ristocetin-induced binding of von Willebrand factor to platelets. Blood. 61:99-110.
12. Shoenfeld, Y., D. A. Isenberg, J. Rauch, M. P. Madaio, B. D. Stollar, and R. S. Schwartz. 1983. Idiotypic cross-reaction of monoclonal human lupus autoantibodies. J. Exp. Med. 158:718-726.

13. Isenberg, D. A., Y. Shoenfeld, M. Madaio, B. D. Stollar, and R. S. Schwartz. 1984. Measurement of anti-DNA antibody idiotypes to monitor the course of SLE. Lancet. ii:422-428.

14. Shoenfeld, Y., and E. Mozes. 1990. Pathogenic idiotypes of antibodies and autoimmunity. FASEB (Fed. Am. Soc. Exp. Biol.) J. 4:2546-2551.

15. Nossent, J. C., V. Huysen, R. J. T. Smeenk, and A. J. G. Swaak. 1989. Low avidity antibodies to dsDNA in SLE: a longitudinal study of their clinical signifcance. Ann. Rheum. Dis. 48:677-682.

16. Smeenk, R. J. T., W. A. M. Lucassen, and A. J. G. Swaask. 1987. Is anticardiolipin activity a cross-reaction of anti-DNA or a separate entity. Arthritis Rheum. 30:607-617.

17. Isenberg, D. A., Y. Shoenfeld, and R. S. Schwartz. 1984. Multiple serological reactions and their relationship to clinical activity in systemic lupus erythematosus. A study of 56 patients. Arthritis Rheum. 27:132-138.

18. Shoenfeld, Y., J. Rauch, H. Massicotte, S. K. Datta, J. A. Schwartz, B. D. Stollar, and R. S. Schwartz. 1983. Polyspecificity of monoclonal lupus antibodies produced by human-human hybridomas. N. Engl. J. Med. 308:414-420.

19. Blank, M., M. Krup, S. Mendelovic, H. Fricke, E. Mozes, N. Talal, A. R. M. Coates, and Y. Shoenfeld. 1990. The importance of the pathogenic $16 / 6$ idiotype in the induction of SLE in naive mice. Scand. J. Immunol. 31:45-52.

20. Shoenfeld, Y., H. Amital-Teplizki, S. Mendelovic, M. Blank, E. Mozes, and D. A. Isenberg. 1989. The role of the human anti-DNA idiotype $16 / 6$ in autoimmunity. Clin. Immunol. Immunopathol. 51:313-325. 